\title{
Assessment of an Educational Intervention on the Perception of Adolescent Girls towards Menstrual Hygiene in Ogun State, Nigeria
}

\author{
Ugochinyere Chinasa Ekeanyanwu*, Chinomso Adanma Uzoechi \\ Department of Public Health, Babcock University, Ilishan Remo, Ogun State, Nigeria
}

\begin{abstract}
In low and middle-income countries, menstruation is impeded by several misconceptions, taboos and shrouded in secrecy. This serves as a major challenge to proper Education regarding menstrual hygiene and has blocked the access of adolescent girls to the right kind of information, thereby influencing a negative outcome associated with harmful behaviours. The objective of the study was to investigate the assessment of an educational intervention on the perception of adolescent girls towards menstrual hygiene in Ogun state, Nigeria. The study utilized a quasi-experimental design. One hundred and twenty (120) in-school adolescent girls were selected through a multistage sampling technique from four (4) secondary schools within four (4) local government areas in Ogun State, Nigeria. A validated 23-items questionnaire measured on a 69-point rating scale with a Cronbach Alpha scores 0.79 was used for data collection. The mean $\pm S D$ age and age at menarche of adolescent girls was 14.92 $\pm 1.82 ; 12.73 \pm 1.38$. The majority of respondents had low scores of perceptions. The educational intervention had an effective change in the level of perception of adolescent schoolgirls between baseline and the $6^{\text {th }}$-week follow-up, indicating a mean difference of $26.70(p<0.01)$ for the peer-led, 26.54( $p<0.01)$ parent-led, 20.16( $p<0.01)$ parent and peer-led and a decrease in mean in the control group $(-0.17 ; p=0.866)$. The peer-led educational approach had a better impact on adolescent girls' perception compared to other educational approaches. Hence, this is an indication that peer-education strategies should be utilized for further interventions and in reaching out to adolescents.
\end{abstract}

Keywords: Adolescent girls, educational intervention, Menstrual Hygiene, Parent-led, Peer-led, Perception.

\section{Introduction}

Menstruation is a normal physiological phenomenon and a major phase where a woman undergoes certain reproductive changes [1]. This occurs during the years between puberty and menopause except during pregnancy [2].

During menstruation, hygiene is an inevitable part of a woman's and a girl's life, which is associated with their health and wellbeing [3, 4]. However, menstrual hygiene can be defined as making use of clean, hygienic menstrual material to absorb blood that can be changed in privacy as often as possible; making use of soap and water for washing the body as required and being able to dispose of used menstrual waste properly [5]. In low and middle-income countries such as Nigeria, several misconceptions are linked with menstruation as it is considered as something that should be suffered in silence and 'shrouded in secrecy [6]. Menstruating women and girls are believed to be impure and contaminated and have limited or no access to appropriate toilets and facilities for handwashing [7].

Furthermore, many adults, as well as parents and close relations in Nigeria, are hesitant to openly discuss issues regarding sexual health, reproduction, and menstruation [8]. As a result, it serves as a major challenge to proper 
Education regarding menstrual hygiene and has blocked the access of adolescent girls to the right kind of information, especially in the rural and tribal communities [6,9].

This does not only have medical implications such as reproductive tract infections, urinary tract infections, and other complications but influences negative outcomes associated with harmful behaviours [8].

Many skills such as open communication have been used for having countercultural conversations around menstrual hygiene and towards changing misconceptions but were less effective. By breaking this chain of silence, enhancing these communication skills amongst adolescent girls by the use of the health belief model could produce a desirable change in the perception of menstrual hygiene [10].

The health belief model proposes that a person's belief in the efficiency of the recommended health behaviour will predict the likelihood of the person to adopt the behaviour and that an individual's course of action often depends on the perceptions of the person's benefits and barriers related to health behaviour [11]. The purpose of the study was to investigate the assessment of an educational intervention on the perception of adolescent girls towards menstrual hygiene in Ogun state, Nigeria.

\section{Materials and Methods}

The study was a quasi-experimental design that comprised of three experimental and a control group to investigate the assessment of an educational intervention on the perception of adolescent girls towards menstrual hygiene in selected public secondary schools in Ogun State, Nigeria.

The multistage sampling technique was utilized in selecting the participants. Ogun East senatorial district was purposively selected, and from this senatorial district, four local government areas were selected through balloting. After which from the ministry of Education, the list of public secondary schools was obtained, and one school was selected from each of the local government areas.

Purposive sampling technique was used to select adolescent girls that were between the ages of 10-19 from JS1-SS2, and based on the sample required, a systematic sampling technique was used to proportionate the size of the total study unit accounted for each school using every $12^{\text {th }}$ person on the class list. Three peer educators who were class prefects and an assistant of the school were selected, and two parents (mothers) of the study participants were recruited with the consent of the principal of the various school. They were all trained for one week, after which they were evaluated.

The study population was in-school adolescent girls between the ages of 10-19 in selected public secondary schools in Ogun state. Adolescent girls who attained menarche, who were fully registered in a public secondary school within the rural areas, who were willing to participate and whose parents gave their consent as well as parents(mothers) of the participants who were interested and willing to participate were the criteria for the study.

The exclusion criteria were adolescent girls who did not attain menarche and were above and below 10-19 years, who were not fully registered for the term, who were reluctant and whose parents did not give consent, as well as parents(mothers) of the participants who were not interested and willing to participate.

The sample size was derived from the computation using a level of significance of $95 \%$ and $80 \%$ power. There was no given estimate of the prevalence of poor menstrual hygiene in secondary school female adolescents in Ogun state. Thus, the sample size was determined using the prevalence at $50 \%$.

$$
n=\left(z_{a}+z_{\beta}\right)_{2} X P_{0}\left(1-P_{0}\right) /\left(P_{1}-P_{0}\right)_{2}
$$

Where $\mathrm{n}$ is the minimum sample size per group.

$$
\begin{aligned}
Z_{\alpha}= & 95 \% \text { confidence interval i.e., } 1.96 \\
Z_{\beta}= & 80 \% \text { i.e., } 0.84 \text { (Power to detect } \\
& \text { changes in the outcome variable and }
\end{aligned}
$$




$$
\begin{gathered}
\mathrm{P}_{0}=\begin{array}{l}
\text { avoid type II error) } \\
\text { prevalence (at 50\%) } \\
\mathrm{P}_{1}=\begin{array}{l}
80 \% \quad \text { (desired level of outcome } \\
\text { variable })
\end{array} \\
n=\frac{(1.96+0.84)^{2} \times 0.5(1-0.5)}{(0.8-0.5)^{2}} \\
\frac{(2.8)^{2} \times 0.5(0.5)}{(0.8-0.5)^{2}} \\
\frac{7.84 \times 0.25}{0.09} \\
=21.78 \cong 22
\end{array}
\end{gathered}
$$

The minimum sample size was $22.10 \%$ was added to the minimum sample size to take care of attrition. The total number of participants after adding $10 \%$ of 22 was $22+2.2=24 \simeq 30$.

Approximately 30 participants per group were considered for the study. Based on the computation, a total number of 120 participants (30 per group $X$ 4) from the four selected secondary schools was considered for the study (representing 30 people per group).

A quantitative approach was utilized for the study. The Instrument was developed using information gathered from a review of literature. The instrument was a semi-structured and participant questionnaire, which sought information on socio-demographic characteristics and perception of in-school adolescent girls in selected public secondary schools towards menstrual hygiene in Ogun State, Nigeria. The same instrument was administered at baseline, immediate postintervention, and 6-week follow-up. The instrument was sectioned as follows:

\section{Section A}

Socio-demographic characteristics of the participants that were relevant to the study included their age, age at first period (menarche), class, religion, ethnic origin, mothers' level of Education, and occupation.

\section{Section B}

Perception of participants towards menstrual hygiene comprised of the perception domain that was operationalized by sub-variables perceived susceptibility; perceived severity/seriousness; perceived benefits; perceived barriers, and perceived self-efficacy. All variables were made up of questions with a 23-item statement which investigated if respondents strongly agreed, agreed, undecided, disagreed, or strongly disagreed.

In scoring the items, the positively constructed questions, strongly agree (SA) was scored 3, Agree (A) was scored 2, Undecided (UD) 0, Disagree (D) 1, and Strongly Disagree (SD) scored 0 . While the negatively constructed questions, strongly agree (SA) was scored 0 , Agree (A) was scored 1, Undecided (UD) 0, Disagree (D) 2, and Strongly Disagree (SD) 3; and an index of 69 points was generated. The score of the respondents was adjudged to either have a low or high perception.

To ascertain the reliability of the instrument, a test-retest was conducted for internal consistency of the instrument using $10 \%$ of the anticipated sample size. The instrument was distributed to 10 in-school female adolescents in a public secondary with the same characteristics. The reliability score generated was 0.79 using the Cronbach alpha standard score. Ethical approval was obtained from Babcock University Health Research and Ethics Committee [BUHREC]; the Ministry of Health Research Ethics and Ministry of Education Planning Research and statistics, Ogun State to conduct the study. A letter of introduction was also be presented to the head of each school to be used for the study. All participants were informed that their participation was voluntary, and informed consent was sought from all participants prior to their participation. Confidentiality of participants was maintained, as no personal identifying information was not collected on the questionnaire.

\section{Results}

A total of one hundred and twenty (120) inschool adolescent girls were recruited from four junior and senior secondary schools in four 
local government areas in Ogun State, Nigeria, to take part in the intervention. Each of the intervention and control groups had an equal amount of 30 participants at baseline, postintervention, and follow-up periods. The response rate after the health intervention was administrated was $100 \%$.

There were more adolescent girls who were between the age bracket of 14-16 years across the intervention groups and more adolescent girls between the age bracket of 17-19 years in the control group. The overall mean $\pm \mathrm{SD}$ age at menarche in this study was $12.73 \pm 1.38$ years (Table 1). The adolescent girls have recruited from the junior secondary school class 1- 3 and senior secondary school classes 1 to 3 , and the majority were Christians who only a few were reported to be a traditionalist. The ethnic distribution showed that the majority were from the Yoruba ethnic group (Table 2).

Table 1. Socio-demographic Characteristics of Adolescent Girls in the Intervention and Control Groups: Age and Age at Menarche

\begin{tabular}{|l|l|l|l|l|}
\hline \multirow{2}{*}{ Variables } & Parent-Led & Peer-Led & Parent-Led and Peer-Led & Control \\
\cline { 2 - 5 } & $\mathbf{N}(\%)$ & $\mathbf{N}(\%)$ & $\mathbf{N}(\%)$ & $\mathbf{N}(\%)$ \\
\hline Age in years & \multicolumn{5}{|l|}{} \\
\hline $\mathbf{1 0}-\mathbf{1 3}$ & $9(30.0)$ & $7(23.3)$ & $12(40.0)$ & $5(16.7)$ \\
\hline $\mathbf{1 4}-\mathbf{1 6}$ & $15(50.0)$ & $20(66.7)$ & $17(56.7)$ & $9(30.0)$ \\
\hline $\mathbf{1 7}-\mathbf{1 9}$ & $6(20.0)$ & $3(10.0)$ & $1(3.3)$ & $16(53.3)$ \\
\hline Total & $30(100)$ & $30(100)$ & $30(100)$ & $30(100)$ \\
\hline Mean \pm SD & $14.83 \pm 1.91$ & $14.77 \pm 1.48$ & $13.93 \pm 1.48$ & $16.17 \pm 1.70$ \\
\hline Age at Menarche & & $12.83 \pm 0.87$ \\
\hline Mean \pm SD & $12.97 \pm 1.47$ & $13.07 \pm 1.70$ & $12.07 \pm 1.17$ & $30(100)$ \\
\hline Total & $30(100)$ & $30(100)$ & $30(100)$ & \\
\hline
\end{tabular}

Table 2. Socio-demographic Characteristics of Adolescent girls in the Intervention and Control Groups: Class, Religion and Ethnic Group

\begin{tabular}{|l|l|l|l|l|}
\hline \multirow{2}{*}{ Variables } & Parent-Led & Peer-Led & Parent-Led and Peer-Led & Control \\
\cline { 2 - 6 } & $\mathbf{N}(\%)$ & $\mathbf{N}(\%)$ & $\mathbf{N}(\%)$ & $\mathbf{N}(\%)$ \\
\hline Class & $7(23.3)$ & $10(33.3)$ & $7(23.3)$ & $6(20.0)$ \\
\hline JS 1 & $7(23.3)$ & $6(20.0)$ & $6(20.0)$ & $10(33.3)$ \\
\hline JS 2 & $5(16.7)$ & $5(16.7)$ & $6(20.0)$ & $6(20.0)$ \\
\hline SS 3 & $6(20.0)$ & $4(13.3)$ & $6(20.0)$ & $3(10.0)$ \\
\hline SS 2 & $5(16.7)$ & $5(16.7)$ & $5(16.7)$ & $5(16.7)$ \\
\hline Total & $\mathbf{3 0}(\mathbf{1 0 0})$ & $\mathbf{3 0}(\mathbf{1 0 0})$ & $\mathbf{3 0}(\mathbf{1 0 0})$ & $\mathbf{3 0}(\mathbf{1 0 0})$ \\
\hline Religion & & & $20(66.7)$ & $18(60.0)$ \\
\hline Christianity & $23(76.7)$ & $22(73.3)$ & $20.7)$ & $12(40.0)$ \\
\hline Islam & $6(20.0)$ & $8(26.7)$ & $10(33.3)$ & $0(0.0)$ \\
\hline Traditional & $1(3.3)$ & $0(0.0)$ & $0(0.0)$ & $27(90.0)$ \\
\hline Ethnic Group & $26(86.7)$ & $26(86.7)$ & $24(80.0)$ & $1(3.3)$ \\
\hline Yoruba & $0(0.0)$ & $4(13.3)$ & $6(20.0)$ & $2(6.7)$ \\
\hline Igbo & $1(3.3)$ & $0(0.0)$ & $0(0.0)$ & $0(0.0)$ \\
\hline Others & $1(3.3$ & $0(0.0)$ & $0(0.0)$ & $\mathbf{3 0}(\mathbf{1 0 0})$ \\
\hline Total & $\mathbf{3 0}(\mathbf{1 0 0})$ & $\mathbf{3 0}(\mathbf{1 0 0})$ & $\mathbf{3 0}(\mathbf{1 0 0})$ &
\end{tabular}


The results also disclosed that across the four groups, the majority of the adolescent girls' mothers had at least secondary or tertiary
Education and were businesswomen or traders (Table 3).

Table 3. Socio-demographic Characteristics of Adolescent Girls in the Intervention and Control Groups: Mother's Level of Education and Mother's Occupation

\begin{tabular}{|l|l|l|l|l|}
\hline \multirow{2}{*}{ Variables } & Parent-Led & Peer-Led & Parent-Led and Peer-Led & Control \\
\cline { 2 - 6 } & $\mathbf{N}(\boldsymbol{\%})$ & $\mathbf{N}(\boldsymbol{\%})$ & $\mathbf{N}(\%)$ & $\mathbf{N}(\%)$ \\
\hline \multicolumn{5}{|l|}{ Mother's Level of Education } \\
\hline No Formal Education & $8(26.7)$ & $3(10.0)$ & $5(16.7)$ & $6(20.0)$ \\
\hline Primary & $1(3.3)$ & $4(13.3)$ & $0(0.0)$ & $3(10.0)$ \\
\hline Secondary & $15(50)$ & $14(46.7)$ & $20(66.7)$ & $17(56.7)$ \\
\hline Tertiary & $6(19.9)$ & $9(30.0)$ & $5(16.7)$ & $4(13.3)$ \\
\hline Total & $\mathbf{3 0}(\mathbf{1 0 0})$ & $\mathbf{3 0}(\mathbf{1 0 0})$ & $\mathbf{3 0}(\mathbf{1 0 0})$ & $\mathbf{3 0}(\mathbf{1 0 0})$ \\
\hline Mother's Occupation & & & $25(83.3)$ \\
\hline Business/Trading & $19(63.3)$ & $24(80.0)$ & $26(86.7)$ & $2(6.7)$ \\
\hline Housewife & $4(13.3)$ & $2(6.7)$ & $1(3.3)$ & $1(3.3)$ \\
\hline Farmer & $4(13.3)$ & $1(3.3)$ & $2(6.7)$ & $1(3.3)$ \\
\hline Teacher & $2(6.7)$ & $1(3.3)$ & $1(3.3)$ & $1(3.3)$ \\
\hline Others & $1(3.3)$ & $2(6.7)$ & $0(0.0)$ & $\mathbf{3 0}(\mathbf{1 0 0})$ \\
\hline Total & $\mathbf{3 0}(\mathbf{1 0 0})$ & $\mathbf{3 0}(\mathbf{1 0 0})$ & $\mathbf{3 0}(\mathbf{1 0 0})$ &
\end{tabular}

Regarding the awareness of menstrual hygiene among adolescent's girls in this study, $20(66.7 \%)$ in the parent-led, $24(80 \%)$ in the peer-led and 26 (86.7) in the parent and peer- led reported to have been aware of menstrual hygiene and the information were sourced from mothers, teachers, sisters, and relatives (Table 4).

Table 4. Adolescent Girls' Awareness of Menstrual Hygiene

\begin{tabular}{|c|c|c|c|c|c|}
\hline \multirow{2}{*}{ Variables } & Parent-Led & Peer-Led & Parent-Led and Peer-Led & Control & \multirow{2}{*}{ P Value } \\
\hline & $\mathbf{N}(\%)$ & $\mathbf{N}(\%)$ & $\mathbf{N}(\%)$ & $\mathbf{N}(\%)$ & \\
\hline \multicolumn{6}{|c|}{ Heard about Menstrual Hygiene? } \\
\hline Yes & $20(66.7)$ & $21(70.0)$ & $24(80.0)$ & $26(86.7)$ & \multirow[t]{3}{*}{$0.247^{\mathrm{a}}$} \\
\hline No & $10(33.3)$ & $9(30.0)$ & $6(20.0)$ & $4(13.3)$ & \\
\hline Total & $30(100)$ & $30(100)$ & $30(100)$ & $30(100)$ & \\
\hline \multicolumn{6}{|c|}{ Source of Menstruation Hygiene Information } \\
\hline Not Informed & $10(33.3)$ & $9(30.0)$ & $6(20.0)$ & $4(13.3)$ & \multirow{8}{*}{$0.009^{b^{*}}$} \\
\hline Mother & $12(40.0)$ & $6(20.0)$ & $13(43.3)$ & $18(80.0)$ & \\
\hline Sister & $3(10.0)$ & $2(6.7)$ & $3(10.0)$ & $8(26.7)$ & \\
\hline Friends & $0(0.0)$ & $3(10.0)$ & $1(3.3)$ & $0(0.0)$ & \\
\hline Relative & $0(0.0)$ & $2(6.7)$ & $2(6.7)$ & $0(0.0)$ & \\
\hline Teacher & 4 (13.3) & $8(26.7)$ & $5(16.7)$ & $0(0.0)$ & \\
\hline Media & $1(3.3)$ & $0(0.0)$ & $0(0.0)$ & $0(0.0)$ & \\
\hline Total & 30 (100) & 30 (100) & $30(100)$ & 30 (100) & \\
\hline
\end{tabular}




\section{Baseline Distribution of Adolescent Girls Perception Towards Menstrual Hygiene}

The level of perception were made up of questions with a 23-item statement, which was sectioned to assess the perceived susceptibility, perceived severity, perceived barriers, perceived benefits, and perceived self-efficacy. The responses were grouped, and the results indicated that over half of the total populace had low scores of perceived susceptibilities to menstruation-related infections across the four groups. Regarding the severity or seriousness of the infection, barriers, and benefits of practicing menstrual hygiene, above a quarter of the respondents had high scores of perceptions in the parent-led, peer-led, parent and peer-led, and control groups, respectively. While below quarter across the intervention and control groups had a low score of perceived selfefficacy towards menstrual hygiene (Table 5).

The overall distribution in the level of perception of adolescent girls showed that about half had a low score of perception; and with a 69-point rating scale, the mean \pm SD scores for each group were $34.33 \pm 10.99$, $36.10 \pm 7.45,37.77 \pm 7.34,34.20 \pm 4.76$ for parentled, peer-led, parent and peer-led and control groups respectively (Table 5).

Table 5. Baseline Distribution of Adolescents Girls Perception towards Menstrual Hygiene

\begin{tabular}{|c|c|c|c|c|c|}
\hline \multirow[t]{2}{*}{ Perception } & $\begin{array}{l}\text { Parent-led } \\
\text { Group }\end{array}$ & $\begin{array}{l}\text { Peer-led } \\
\text { Group }\end{array}$ & $\begin{array}{l}\text { Parent and } \\
\text { Peer-led }\end{array}$ & Control & \multirow[t]{2}{*}{ p-value } \\
\hline & Mean \pm SD & Mean \pm SD & Mean \pm SD & Mean \pm SD & \\
\hline Perceived Susceptibility & \multicolumn{5}{|c|}{ Measured on a 12-point rating scale } \\
\hline Low $(0-6)$ & $12(80.0)$ & $21(70.0)$ & $18(60.0)$ & $24(80.0)$ & \multirow{4}{*}{$0.252^{\mathrm{a}}$} \\
\hline $\operatorname{High}(6.1-12)$ & $6(20.0)$ & $9(30.0)$ & $12(40.0)$ & $6(20.0)$ & \\
\hline Total & $30(100)$ & $30(100)$ & $30(100)$ & $30(100)$ & \\
\hline Mean \pm SD & $3.27 \pm 2.741$ & $4.77 \pm 2.99$ & $6.13 \pm 2.43$ & $4.83 \pm 2.12$ & \\
\hline Perceived Severity & \multicolumn{5}{|c|}{ Measured on a 12-point rating scale } \\
\hline Low $(0-6)$ & $19(63.3)$ & $12(40.0)$ & $16(53.3)$ & $14(46.7)$ & \multirow{4}{*}{$0.319^{\mathrm{a}}$} \\
\hline High $(6.1-12)$ & $11(36.7)$ & $18(60.0)$ & $14(46.7)$ & $16(53.3)$ & \\
\hline Total & $30(100)$ & $30(100)$ & $30(100)$ & $30(100)$ & \\
\hline Mean \pm SD & $5.87 \pm 2.62$ & $6.80 \pm 2.61$ & $6.17 \pm 2.07$ & $6.47 \pm 2.11$ & \\
\hline Perceived Barriers & \multicolumn{5}{|c|}{ Measured on a 15-point rating scale } \\
\hline Low $(0-7.5)$ & $18(60.0)$ & $20(66.7)$ & $18(53.3)$ & $26(86.7)$ & \multirow{4}{*}{$0.038^{\mathrm{a}}$} \\
\hline High $(7.51-15)$ & $12(40.0)$ & $10(33.3)$ & $14(46.7)$ & $4(13.3)$ & \\
\hline Total & $30(100)$ & $30(100)$ & $30(100)$ & $30(100)$ & \\
\hline Mean \pm SD & $7.37 \pm 3.01$ & $6.13 \pm 2.89$ & $6.80 \pm 3.15$ & $5.43 \pm 2.11$ & \\
\hline Perceived Benefits & \multicolumn{5}{|c|}{ Measured on a 15-point rating scale } \\
\hline Low $(0-7.5)$ & $7(23.3)$ & $8(26.7)$ & $2(6.7)$ & $18(60.0)$ & \multirow{4}{*}{$0.762^{\mathrm{a}}$} \\
\hline High $(7.51-15)$ & $23(76.7)$ & $22(73.3)$ & $28(93.3)$ & $12(40.0)$ & \\
\hline Total & $30(100)$ & $30(100)$ & $30(100)$ & $30(100)$ & \\
\hline Mean \pm SD & $9.13 \pm 3.53$ & $9.67 \pm 2.85$ & $10.70 \pm 2.68$ & $6.23 \pm 3.04$ & \\
\hline Perceived Self-Efficacy & \multicolumn{5}{|c|}{ Measured on a 15-point rating scale } \\
\hline Low $(0-7.5)$ & $10(33.3)$ & $13(43.3)$ & $5(16.7)$ & $2(6.7)$ & \multirow[t]{4}{*}{$0.052^{\mathrm{a}}$} \\
\hline High $(7.51-15)$ & $20(66.7)$ & $17(56.7)$ & $25(83.3)$ & $28(93.3)$ & \\
\hline Total & $30(100)$ & $30(100)$ & $30(100)$ & $30(100)$ & \\
\hline Mean \pm SD & $8.70 \pm 5.79$ & $8.73 \pm 3.88$ & $9.97 \pm 3.22$ & $11.23 \pm 2.57$ & \\
\hline Perception & \multicolumn{5}{|c|}{ Measured on a 69-point rating scale } \\
\hline
\end{tabular}




\begin{tabular}{|l|l|l|l|l|l|}
\hline Low $(0-34.5)$ & $12(40.0)$ & $15(50.0)$ & $7(23.3)$ & $16(53.3)$ & \\
\cline { 1 - 5 } High $(34.51-69)$ & $18(60.0)$ & $15(50.0)$ & $23(76.7)$ & $14(46.7)$ & \multirow{2}{*}{$0.082^{\mathrm{a}}$} \\
\cline { 1 - 5 } Total & $\mathbf{3 0}(\mathbf{1 0 0})$ & $\mathbf{3 0}(\mathbf{1 0 0})$ & $\mathbf{3 0}(\mathbf{1 0 0})$ & $\mathbf{3 0}(\mathbf{1 0 0})$ & \\
\cline { 1 - 4 } \pm Mean & $\mathbf{3 4 . 3 3} \pm \mathbf{1 0 . 9 9}$ & $\mathbf{3 6 . 1 0} \pm \mathbf{7 . 4 5}$ & $\mathbf{3 7 . 7 7} \pm 7.34$ & $\mathbf{3 4 . 2 0} \pm \mathbf{4 . 7 6}$ & \\
\hline
\end{tabular}

P-value obtained by Chi-Square test

*Significant at $<0.05$

\section{Assessment of Educational Intervention on Adolescent Girls Perception of Menstrual Hygiene}

The assessment of the educational Intervention of adolescent schoolgirls perception of menstrual hygiene measured on a 69-point rating scale was assessed at immediate post-intervention. The results indicated changes in the mean score across groups were statistically significant at $p<0.01$.
The assessment was also conducted at $6^{\text {th }}$ week follow-up, and the results showed that there were changes in the mean score across the four groups parent-led, peer-led, parent and peer-led intervention, and control groups. The evaluation showed that the majority of the adolescent schoolgirls in the three intervention groups scored between 34.51 - 69 points, and the peer-led intervention group recorded the highest mean score (Table 6).

Table 6. Assessment of Educational Intervention on Adolescent Girls Perception of Menstrual Hygiene

\begin{tabular}{|c|c|c|c|c|c|}
\hline \multirow{2}{*}{ Perception } & Parent-led Group & Peer-led Group & Parent and Peer Group & Control & \multirow{2}{*}{ P-Value } \\
\hline & $\mathbf{N}(\%)$ & $\mathbf{N}(\%)$ & $\mathbf{N}(\%)$ & $\mathbf{N}(\%)$ & \\
\hline \multicolumn{6}{|l|}{ Baseline } \\
\hline Low $(0-34.5)$ & $12(40.0)$ & $15(50.0)$ & $7(23.3)$ & $16(53.3)$ & \multirow[t]{4}{*}{$0.082^{\mathrm{a}}$} \\
\hline High (34.51-69) & $18(60.0)$ & $15(50.0)$ & $23(76.7)$ & $14(46.7)$ & \\
\hline Total & $30(100)$ & $30(100)$ & $30(100)$ & $30(100)$ & \\
\hline Mean \pm SD & $34.33 \pm 10.99$ & $36.10 \pm 7.45$ & $37.77 \pm 7.34$ & $34.20 \pm 4.76$ & \\
\hline \multicolumn{6}{|c|}{ Post Intervention } \\
\hline Low $(0-34.5)$ & $0(0.0)$ & $0(0.0)$ & $0(0.0)$ & $18(60.0)$ & \multirow[t]{4}{*}{0.000} \\
\hline $\operatorname{High}(34.51-69)$ & $30(100.0)$ & $30(100.0)$ & $30(100)$ & $12(34.0)$ & \\
\hline Total & $30(100)$ & $30(100)$ & $30(100)$ & $30(100)$ & \\
\hline Mean \pm SD & $59.87 \pm 4.13$ & $61.87 \pm 2.85$ & $58.67 \pm 4.48$ & $34.00 \pm 6.01$ & \\
\hline \multicolumn{6}{|l|}{ 6-weeks Follow Up } \\
\hline Low $(0-34.5)$ & $0(0.0)$ & $0(0.0)$ & $0(0.0)$ & $18(60.0)$ & \multirow{4}{*}{0.000} \\
\hline $\operatorname{High}(34.51-69)$ & $30(100)$ & $30(100.0)$ & $30(100.0)$ & $12(40.0)$ & \\
\hline Total & $30(100)$ & 30 (100) & 30 (100) & 30 (100) & \\
\hline Mean \pm SD & $60.87 \pm 3.83$ & $62.80 \pm 2.95$ & $59.93 \pm 3.85$ & $34.03 \pm 0.05$ & \\
\hline
\end{tabular}

\section{Change in Adolescent Girls Perception of Menstrual Hygiene from Baseline to 6th Week Follow-Up}

At the end of the intervention, the peer-led educational group had a statistically significant change in the means of adolescent schoolgirls' perception of menstrual hygiene. The mean difference observed was $26.70(\mathrm{p}<0.01)$. In the parent-led educational group, the mean difference was $26.54(\mathrm{p}<0.01)$; while the parent and peer-led educational group was 20.16 $(\mathrm{p}<0.01)$. The control group had a mean difference of -0.17 which was not statistically significant $(p=0.866)$ (Table 7). 


\section{Research Hypothesis}

There is no significant difference in the level of perception towards menstrual hygiene among in-school female adolescents between baseline and $6^{\text {th }}$-week follow-up. A paired T-test analysis was conducted to determine the results. The results indicated that the observed difference in the mean in the peer-led group $(\Delta$ $\left.=26.70 ; \mathrm{t}_{29}=17.573 ; \mathrm{p}<0.01\right)$, Parent-led group
$\left(\Delta=26.54 ; \mathrm{t}_{29}=14.357 ; \mathrm{p}<0.01\right)$ and parent and peer-led group $\left(\Delta=20.16 ; \mathrm{t}_{29}=19.379\right)$ were statistically significant (see Table 7).

The null hypothesis is therefore rejected. This indicates that there is a statistically significant difference as a result of the educational interventions conducted on the perception of adolescent schoolgirls in Ogun State, Nigeria.

Table 7. Change in Adolescent Girls Perception of Menstrual Hygiene from Baseline to 6th Week Follow-Up

\begin{tabular}{|c|c|c|c|c|c|c|c|}
\hline Variable: Perception & $\mathbf{N}$ & Mean Diff & ES (CI) & SE & df & $\mathbf{t}$ & Sig \\
\hline \multicolumn{8}{|l|}{ Peer-led } \\
\hline Baseline & \multirow{2}{*}{30} & \multirow{2}{*}{26.70} & \multirow{2}{*}{$4.79(3.38-6.20)$} & $36.10(1.36)$ & \multirow{2}{*}{29} & \multirow{2}{*}{17.573} & \multirow{2}{*}{$0.000^{\mathrm{a} *}$} \\
\hline 6-weeks follow up & & & & $62.80(0.54)$ & & & \\
\hline \multicolumn{8}{|l|}{ Parent-Led } \\
\hline Baseline vs & \multirow{2}{*}{30} & \multirow{2}{*}{26.54} & \multirow{2}{*}{$3.28(1.23-5.33)$} & $34.33(2.01)$ & \multirow{2}{*}{29} & \multirow{2}{*}{14.357} & \multirow{2}{*}{$0.000^{\mathrm{a} *}$} \\
\hline 6-weeks follow up & & & & $60.87(0.70)$ & & & \\
\hline \multicolumn{8}{|l|}{ Parent and Peer-led } \\
\hline Baseline vs & \multirow{2}{*}{30} & \multirow{2}{*}{20.16} & \multirow{2}{*}{$3.50(2.04-4.96)$} & $39.77(1.34)$ & \multirow{2}{*}{29} & \multirow{2}{*}{19.379} & \multirow{2}{*}{$0.000^{\mathrm{a} *}$} \\
\hline 6-weeks follow up & & & & $59.93(0.70$ & & & \\
\hline \multicolumn{8}{|l|}{ Control } \\
\hline Baseline vs & \multirow{2}{*}{30} & \multirow{2}{*}{-0.17} & \multirow{2}{*}{$-0.03(1.39-1.32)$} & $34.20(0.87)$ & \multirow{2}{*}{29} & \multirow{2}{*}{0.171} & \multirow[t]{2}{*}{$0.866^{\mathrm{a} *}$} \\
\hline 6-weeks follow up & & & & $34.03(1.10)$ & & & \\
\hline
\end{tabular}

${ }^{a} \mathrm{p}$-value obtained by t-test

*Significant at $\mathrm{p}<0.05$

\section{Discussion}

The study measured the perception of adolescent schoolgirls towards menstrual hygiene practices developed in line with the constructs from the Health Belief Model. The mean age $\pm \mathrm{SD}$ of the menarche in the present study was discovered to be $12.73 \pm 1.38$ years which is similar to that of the mean age reported among adolescent girls of Muğla province, Turkey, and comparable to study conducted in Damietta City, Eygpt [12, 13]. Moreover, the majority of adolescent schoolgirls reported to be aware of menstrual hygiene, and distribution of menstrual hygiene awareness had no statistical difference across the four (4) groups at baseline.

Furthermore, at baseline, the scores of the adolescent girls perceived susceptibility to contracting menstruation-related infections, perceived severity of infections and diseases, perceived barriers to menstrual hygiene practice, perceived benefits of menstrual hygiene practice, and self-efficacy to practice menstrual hygiene were assessed.

The results showed that the majority of the adolescent girls had low scores of perceptions towards menstrual hygiene practices. This may have been due to their inadequate knowledge regarding the phenomenon, which builds up the conceptions and beliefs in a society that is directly linked with the menstrual hygiene practices of adolescent girls. Research has shown that lack of adequate perception could make adolescent girls vulnerable to mental, emotional, and physical problems, especially during their menstrual period, which could lead to anxiety, depression and make them less productive in their studies [14].

The findings of this study are supported by studies conducted in southeast Nigeria, bo 
district Sierra Leone, Haryana state, India, and Mysore in India, were poor perception towards menstruation among adolescent girls were reported [14-17]. Adolescents' misconceptions about menstruation cut across cultures and regions. Adolescents in both industrialized and developing nations have varied degrees of erroneous perceptions of menstruation and the menstrual cycle.

This study was effective in increasing the perception scores of the adolescent schoolgirls after the educational intervention. These findings agree with the results of other studies conducted in Bangalore, India, urban community areas of Pune, India, and in Iran [18-20]. The mean scores for the adolescent schoolgirls' perception across the three intervention groups also increased after the follow-up evaluation that was statistically significant.

This indicates that an effective communication skill amongst adolescent girls by the use of theory-based intervention can produce a desirable change in perception and will assure the total reproductive well-being of future generations.

\section{Conclusion}

This study highlighted the importance of breaking free from traditional menstrual beliefs,

\section{References}

[1] Deshpande, T.N., Patil, S.S., Gharai, S.B., Patil, S.R. and Durgawale, P.M., 2018. Menstrual hygiene among adolescent girls-A study from urban slum area. Journal of family medicine and primary care, 7(6), p.1439.

[2] Begum, M., Das, S. and Sharma, H.K., 2016. Menstrual disorders: causes and natural remedies.

Journal of Pharmaceutical, Chemical, and Biological Sciences, 4(2), pp.307-20.

[3] Sharma, N., Shekhawat, R., Gaur, K., Meena, K.K., Meena, G.L., Rathore, M., Verma, M., Raj, D., Yadav, R. and Kewalramani, S., 2019. Assessment of knowledge and practice regarding myths, and constraints and also demonstrated that adolescent girls' perception could be changed through a multi-educational approach. The peer-led educational approach had a better impact and effect size compared to other educational approaches used in this study.

Hence, this is an indication that peereducation strategies should be utilized for further interventions and in reaching out to adolescents. Future researchers could develop interventions for out-of-school adolescent girls and mothers on the perception of menstrual hygiene practices and prevention of reproductive health infections in other states of the country.

\section{Acknowledgments}

The authors acknowledge Sir \& Lady S.M Ekeanyanwu, the Agbayekhais' as well as the research assistants for their contributions to the success of this study. Also, to Babcock University for creating the platform for academic excellence and to all institutions involved in this research for their support and cooperation.

\section{Conflict of interest}

The authors declare no conflict of interest.

menstrual hygiene among school-going adolescent girls of Jaipur city. J Med Sci Clin Res, 7(7), pp.2808-15.

[4] Coast, E., Lattof, S.R. and Strong, J., 2019. Puberty and menstruation knowledge among young adolescents in low-and middle-income countries: a scoping review. International Journal of Public Health, 64(2), pp.293-304.

[5] Belay, S., Kuhlmann, A.K.S. and Wall, L.L., 2020. Girls' attendance at school after a menstrual hygiene intervention in northern Ethiopia. International Journal of Gynecology \& Obstetrics, 149(3), pp.287-291. 
[6] Ali, S.A., Baloch, M., Riaz, L., Iqbal, A., Riaz, R., Perveen, B., Siddiqui, M., and Ali, A.A., 2020. Perceptions, Practices, and Challenges Regarding Menstrual Hygiene Among Women in Karachi, Pakistan: A Comparison Between General Population and Healthcare Workers. Cureus, 12(8).

[7] Speak Up Africa, 2021. Changing perceptions around menstrual hygiene management and why it's important, Date of access: 05/04/2021. https://www.speakupafrica.org/changing-

perceptions-around-menstrual-hygienemanagement-and-why-its-important/.

[8] MacRae, E.R., Clasen, T., Dasmohapatra, M. and Caruso, B.A., 2019. 'It's like a burden on the head': Redefining adequate menstrual hygiene management throughout women's varied life stages in Odisha, India. PLoS One, 14(8), p.e0220114.

[9] Wiyakeerthi, R., Kalyani, P., Felix, A.J.W. and Govindarajan, P.K., 2016. A Study on Knowledge and Practice of Menstrual Hygiene Among Menstruating Women of Age Group 15-44 Yrs in a Rural Area, Tamilnadu. Journal of Medical Science and Clinical Research, 4, pp.13264-13270.

[10] Kashyap, D., 2021. Strategies for improving perceptual skills: 7 strategies, Date of access: 05/04/2021.

https://www.yourarticlelibrary.com/organization/per ception/strategies-for-improving-perceptual-skills-7strategies/63797.

[11] Valizade, R., Taymoori, P., Yousefi, F.Y., Rahimi, L. and Ghaderi, N., 2016. The effect of puberty health education based on health belief model on health behaviors and preventive among teen boys in Marivan, northwest of Iran. International Journal of Pediatrics, 4(8), pp.32713281.

[12] Kipay, S.S., Baybeki, H. And Tabak, R.S., 2016. Impact Of an Interventional Training on Menstrual Hygiene of Adolescent Schoolgirls. Uluslararası Bilimsel Araştırmalar Dergisi (IBAD), 3(2), pp.653-663.

[13]El-Mowafy, R.I., Moussa, M. and El-Ezaby, H.H., 2014. Effect of health education program on knowledge and practices about menstrual hygiene among adolescent girls at the orphanage home. IOSR J Nurs Health Sci, 3(6), pp.48-55.

[14]Preeti, V.K. and Kathpalia, J., 2021. Comparison of perceptions regarding menstruation among women of rural, urban, and slum areas of Gurugram and Mewat.

[15] Adinma, E.D. and Adinma, J.I.B., 2008. Perceptions and practices on menstruation amongst Nigerian secondary school girls. African Journal of Reproductive Health, 12(1), pp.74-83.

[16] Osborne, A., 2020. Assessment of Perceptions and Practices on Menstruation among Adolescent Girls in Five Schools in bo district, Sierra Leone. Journal of Clinical Case Studies Reviews \& Reports. SRC/JCCSR-157. DOI:

https://doi.org/10.47363/JCCSR/2020 (2), 131, p.3.

[17] ML, K., and Ahmed, M., 2016. Awareness, perception, and practices of government preuniversity adolescent girls regarding menstruation in Mysore city, India. International Journal of Community Medicine and Public Health, 3(6), p. 1593.

[18] Solvig, N., Raja, L., George, C.E., O'Connell, B., Gangadharan, P., and Norman, G., 2019. Analysis of knowledge of menstruation, hygiene practices, and perceptions in adolescent girls in India. Modern Health Science, 2(1), pp. p16-p16.

[19]Dumbre, D. and Devi, S., 2019. Effect of Educational Intervention on Menstrual Hygiene on Knowledge, Perception, and Practices of Adolescence Girls. Indian Journal of Public Health Research \& Development, 10(7).

[20] Mohammadinia, N., Rezaei, M.A., Morowatisharifabad, M.A. and Heydarikhayat, N., 2021. The effect of Education based on PEN-3 cultural model on students' menstrual health behaviors: a mixed method study. Health Education Research, 36(2), pp.239-247. 